Citation: Connor, J.P., Kavanagh, D.J., Andrade, J., May, J., Feeney, G.F.X, Gullo, M.J., White, A.M., Fry, M-L., Drennan, J., Previte, J., Tjondronegoro, D. (2014). Alcohol consumption in young adults: the role of multisensory imagery. Addictive Behaviors, 39, 721-724.

\title{
ALCOHOL CONSUMPTION IN YOUNG ADULTS: THE ROLE OF MULTISENSORY IMAGERY
}

Jason P Connor ${ }^{1,2,3^{*}}$, David J. Kavanagh ${ }^{4}$, Jackie Andrade ${ }^{5}$, Jon May ${ }^{5}$, Gerald F.X. Feeney ${ }^{1,3}$,

Matthew J. Gullo ${ }^{1,3}$, Angela M. White ${ }^{1}$, Marie-Louise Fry ${ }^{6}{ }^{\text {Judy Drennan }}{ }^{7}$, Josephine Previte $^{8}$, Dian Tjondronegoro ${ }^{9}$

1. Centre for Youth Substance Abuse Research, The University of Queensland, Australia

2. Discipline of Psychiatry, The University of Queensland, Australia

3. Alcohol and Drug Assessment Unit, Princess Alexandra Hospital, Australia.

4. Institute of Health and Biomedical Innovation, Queensland University of Technology, Australia.

5. School of Psychology, Plymouth University, United Kingdom

6. Department of Marketing, Griffith Business School, Griffith University, Australia

7. QUT Business School, Queensland University of Technology, Australia

8. UQ Business School, The University of Queensland, Australia

9. Science and Engineering Faculty, Queensland University of Technology, Australia

\section{* Corresponding Author:}

Jason P Connor, PhD, FAPS

Director, Centre for Youth Substance Abuse Research, The University of Queensland Australia, 4029

Ph: 00116173365 5150; Fax: 001161733655488

E-mail: Jason.Connor@uq.edu.au 


\begin{abstract}
Little is known about the subjective experience of alcohol desire and craving in young people. Descriptions of alcohol urges continue to be extensively used in the everyday lexicon of young, non-dependent drinkers. Elaborated Intrusion (EI) Theory contends that imagery is central to craving and desires, and predicts that alcohol-related imagery will be associated with greater frequency and amount of drinking. This study involved 1,535 age stratified 1825 year olds who completed an alcohol-related survey that included the Imagery scale of the Alcohol Craving Experience (ACE) questionnaire. Imagery items predicted 12-16\% of the variance in concurrent alcohol consumption. Higher total Imagery subscale scores were linearly associated with greater drinking frequency and lower self-efficacy for moderate drinking. Interference with alcohol imagery may have promise as a preventive or early intervention target in young people.
\end{abstract}

Key Words: Imagery; Craving; Alcohol; Young Adults

Running Title: Multisensory imagery in alcohol consumption

Length: 1993 with in text references

Tables: 1

Figures: 1 


\section{Introduction}

The association between consummatory behavior and craving is well documented (Fortuna, 2012). As there is accumulating evidence that craving plays an important role in substance use disorders (SUD) (Leggio, 2009; Tiffany \& Wray, 2012), the recently released DSM-5 now includes craving or a strong desire or urge to use a substance as a diagnostic SUD criterion (American Psychiatric Association, 2013). There is little research on the role of craving in non-clinical, substance using populations. This is in spite of common reporting of urges and desires for drinking used in the everyday lexicon of non-dependent drinkers. There is some empirical evidence that craving is experienced by young, recreational drinkers (Connor, Feeney, Jack, \& Young 2010; Love, James, \& Willner, 1998; McEvoy, Stritzke, French, Lang, \& Ketterman, 2004). For example, in a sample of college students $(n=309)$, Connor, et al. (2010) found that a widely used measure of alcohol craving, the Obsessive Compulsive Drinking Scale (OCDS, Anton, Moak, \& Latham, 1995), predicted approximately half of the variance in Alcohol Use Disorder Identification Test scores (AUDIT, Saunders, Aasland, Babor, De La Fuente, \& Grant, 1993) and a quarter of the variance in average consumption per drinking occasion.

Definitional and measurement problems have hindered progressing a more comprehensive understanding of craving in both clinical and non-clinical studies. Often measures confound craving with behaviors, or cognitive phenomena such as expectancies, intentions, or perceived behavioral control (Kavanagh, et al., 2013). This has likely inflated estimates of predictive power in previous research and restricted our capacity to disentangle key psychological mechanisms of craving. Broadly, craving can be defined as an affectivelycharged cognitive event in which an object or activity is associated with pleasure or relief of discomfort (Kavanagh, Andrade, \& May, 2005). Reliable and valid measures of alcohol 
craving and desire are now available to capture key components of alcohol craving (e.g., frequency, intensity, salience) (Statham, et al., 2011; Kavanagh, et al., 2013).

A component of craving which has drawn increasing attention is the role of imagery (Kavanagh, et al. 2009). Little is known about the role that imagery plays in non-dependent drinking. Elaborated Intrusion (EI) Theory (Kavanagh, et al., 2005) places sensory imagery at the heart of craving. Vivid sensory imagery is seen as central to desires, eliciting anticipatory consummatory pleasure. Laboratory research in non-clinical samples confirms that imagery is multisensory and accompanies consummatory desires, with more vivid imagery associated with stronger desires (May Andarade, Panabokke, \& Kavanagh, 2004; May, Andrade, Kavanagh \& Penfound, 2008). Competing visual or olfactory imagery are more effective in reducing craving for cigarettes (May, Andrade, Pannabokke, \& Kavanagh, 2010; Versland \& Rosenberg, 2007), food (Kemps \& Tiggemann, 2007; Kemps \& Tiggemann, 2013) and coffee (Kemps \& Tiggemann, 2009), than are auditory imagery or verbal tasks.

The Alcohol Craving Experience (ACE) questionnaire (Statham, et al., 2011), based on EI Theory (Kavanagh, et al., 2005), includes an Imagery scale that measures key sensory components of craving; imagining taste, smell and sensations of drinking. Identifying additional targets of hazardous drinking may result in novel prevention and early intervention approaches for young, 'at risk' drinkers. Recent evidence suggests imagery-based techniques can strengthen behavior change plans and increase the chance of success (Hackman, BennettLevy, \& Holmes, 2011; Knäuper, et al., 2011). An initial step is to assess the relationship between imagery and drinking in a large community sample. Based on laboratory evidence, we expect more vivid imagery will be associated with higher levels of alcohol consumption and harmful use. 


\section{Method}

\subsection{Participants}

A community sample of 1,535 age stratified 18-25 year olds were surveyed online using a market research company. The average age of participants was 22.7 years (SD 2.39), and 54\% were female (816/1522). Ethics approval was obtained from the Queensland University of Technology Human Ethics Research Committee.

\subsection{Measures}

\subsubsection{Alcohol Craving Experience (ACE, Statham, et al., 2011).}

Based on the EI theory of desire (Kavanagh, et al. 2009), the Imagery scale of the ACE (ACE-Imagery, Statham, et al., 2011) measures five sensory aspects of craving (see Table 1: imagining taste, smell, sensations in the mouth, sensations in the body, picturing drinking) and is significantly associated with problem drinking and other features of craving (Statham, et al., 2011). In this study the ACE is scored on a five-point scale from 1 (Not at All) to 5 (Constantly). The ACE- Imagery has excellent internal reliability (.94) and construct validity (Statham, et al., 2011). Internal reliability in the current sample was .95.

\subsubsection{Alcohol Consumption}

Indices of alcohol consumption were assessed to capture range and intensity of drinking over the previous 12 months. Quantity of drinking per day was measured by asking "When you are drinking, how many drinks containing alcohol do you typically consume?” Respondents were shown standard drinks pictures and nominated how many drinks they consumed between Monday and Sunday. Average quantity of drinks per day was then calculated (quantity/frequency). Binge drinking frequency was measured by "How often do you have 
more than 4 drinks on one occasion (in the last month)”. Maximum drinking per drinking occasion was calculated by: "In the last month, what is the maximum number of drinks (on one occasion) you had consumed”. Frequency of drinking was measured by AUDIT Item 1 (Saunders et al., 1993) “How often do you have a drink containing alcohol”? (responses ranged from never to 4 or more times per week).

\subsubsection{Self-Efficacy for Moderate Drinking}

Self-Efficacy was measured by adapting Perugini and Bagozzi (2001) and Bagozzi and Dholakia (2002) scales to the goal of moderate drinking “Thinking about the next 4 weeks, how confident are you that you can maintain moderate drinking behavior ( 4 or less drinks for women; 6 or less drinks for men) if you are [in a particular drinking situation]?” Drinking situations included: at a party with friends, not relaxed in social situations, in a 'shout' [a 'shout' is an Australian colloquial expression which means one's turn to buy drinks for companions at a bar or restaurant, equivalent to a 'round' in UK English"], when wanting to feel more confident, and when offered free drinks. The total score had an internal reliability coefficient of .93.

\subsection{Procedure}

Following consent, questionnaires were administered online to age stratified panel members as a battery that additionally asked about smart phone usage and peer group communication. Questionnaires were de-identified before being returned to researchers. Participants were reimbursed for their participation.

\section{Results}




\subsection{Alcohol Consumption}

On average, participants consumed 1.06 standard drinks (10g alcohol) daily ( $\mathrm{SD}=1.59$, range $0-15.57$ ), exceeded 4+ drinks (in one session) per month an average of 1.97 times (SD $=3.09$, range $0-30$ ) and had an average of 5.01 maximum number of drinks per drinking occasion $(\mathrm{SD}=5.84$, range $0-30)$.

To examine if subsequent findings were influenced by heavier drinking outliers, we removed subjects that scored in the top $10 \%$ of consumption ranges- quantity of drinks per day (.66 standard drinks, $\mathrm{SD}=.68$, range $0-2.57, \mathrm{n}=1382)$, binge drinking frequency $(1.24$ times, $\mathrm{SD}=$ 1.45, range $0-5, \mathrm{n}=1400$ ) and maximum drinking per drinking occasion (3.62 times, $\mathrm{SD}=$ 3.44, range $0-12, n=1393$ ). These supplementary data are applied below (3.2) to assess if heavier drinkers in the sample altered key findings.

\subsection{Imagery and Consumption}

Linear multiple regressions examined the association between ACE Imagery scores and average alcohol consumption per day, 4+ drinks in one session per month, and maximum number of drinks per drinking occasion (Table 1). Imagery items predicted $14.4 \%$ of the variance in average alcohol consumption per day $(F[5,1482]=49.57, p<.001)$, with picture and body would feel items the significant predictors. Sixteen percent of the variance in 4+ drinks in one session per month $(F[5,1481]=56.27, p<.001)$ was predominantly accounted for by three items (picture, taste, body would feel). Imagery items accounted for $12 \%$ of the variance in maximum number of drinks per drinking occasion $(F[5,1485]=40.49, p<.001)$, with picture and smell and body would feel items the significant predictors. 
Supplementary analyses were undertaken with heavier drinkers removed (see 3.1 Alcohol Consumption). Findings were very similar to the full sample: alcohol consumption per day (F $\left.=51.42, p<.001, \mathrm{R}^{2}=13.2 \%\right), 4+$ drinks in one session per month $\left(F=66.55, p<.001, \mathrm{R}^{2}=\right.$ $16.3 \%)$ and maximum number of drinks per drinking occasion $\left(\mathrm{F}=56.09, p<.001, \mathrm{R}^{2}=\right.$ 9.6\%). Standardised beta weights were also similar, with 13 of the 15 replicating significant/non-significant coefficients from the full sample analysis.

All ACE Imagery items had significant zero-order correlations with each of the three drinking indices (Table 1, range .17 to .38, mean .29). The Imagery total score was negatively correlated with the Self-Efficacy for Moderate Drinking Scale $(r=-.34, p<.001)$. Almost identical results were obtained when analyses were run separately for men and women.

----Insert Table 1 here----

ANOVA examined ACE Imagery total scores by frequency of drinking (AUDIT, Saunders, et al., 1993). There was a significant difference between frequency groups, $F(4,1514)=$ 58.87, $p<.001$ ), with all post hoc tests significant at $p<.01$, indicating a clear linear relationship between-Imagery scores and frequency of drinking (Figure 1).

----Insert Figure 1 here----

\section{Discussion}

This is the first large, age stratified community sample investigating components of alcohol craving. Drinking behavior, as measured by average daily alcohol intake, number of occasions drinking more than 4 drinks per session and maximum intake in a drinking session, 
were associated with all sensory image modalities. This further supports EI Theory's assertion that craving involves multisensory imagery (Kavanagh, et al., 2005). Craving imagery explained between $12 \%$ and $16 \%$ of the unique variance in drinking behavior across all measures. More frequent imagery was associated with more frequent drinking.

Visual imagery of alcohol or drinking was a consistent predictor of drinking behavior in this community sample. This additionally supports findings that visual imagery is important in craving for many substances, including food and drink (May et al, 2004; 2008; in submission) and cigarettes (May et al, in submission). It has also been observed in treatment-seeking alcohol use disorder patients (Kavanagh, 2009; Statham 2011). Imagery of how one’s body would feel when drinking, was also a consistent predictor across all indices of drinking behavior. Taste imagery predicted frequency of 4+ drinks in one session and smell imagery predicted maximum number of drinks. Kavanagh et al (2009) reported that imagery of swallowing alcohol correlated with craving duration. The present study found that a similar item, imagery of how alcohol would feel in the mouth or throat, correlated with drinking behavior but did not uniquely predict it. This is possibly because that item was subsumed by the more general 'body feel' item.

This study has limitations. While the sample size was large and craving measurement robust, the cross-sectional design does not allow an assessment of causality or temporal precedence. Findings may not be generalizable to all recreational community drinkers, as we restricted our recruitment to younger drinkers (18-25 years of age). No standardized screening or diagnostic instruments were used to allow exclusion of dependent drinkers, although the range and distribution of consumption indicates that if they were present, prevalence would 
be low. Biological verification of alcohol use over a longer period would have strengthened confidence in self-reported consumption data.

This study confirms the role of multisensory imagery in alcohol craving and extends previous research by showing that this imagery is associated with drinking behavior in a community sample. Consistent with EI Theory, imagery appears to be a strong motivator of behavior. Interventions targeting alcohol craving could include tasks that block visual and 'body feel' imagery, for example, encouraging patients to imagine how good they would feel doing something other than drinking, such as playing football tomorrow without a hangover. To pursue this further a new imagery-based intervention (Functional Imagery Training, FIT) is in the pilot phase. The intention is to strengthen and maintain motivation to control alcohol use by developing imagery about the benefits of reduced consumption, control strategies, and past successes.. 


\section{References}

American Psychiatric Association. (2013). Diagnostic and Statistical Manual of Mental Disorders. (5th ed.). Arlington, VA: Author.

Anton, R. F., Moak, D. H., \& Latham P. (1995). The Obsessive Compulsive Drinking Scale: A self-rated instrument for the quantification of thoughts about alcohol and drinking behaviour. Alcoholism: Clinical and Experimental Research, 19, 92-99.

Bagozzi, R. P., \& Dholakia, U. M. (2002). Intentional social action in virtual communities. Journal of Interactive Marketing, 16, 2-21.

Connor, J.P., Feeney, G.F.X., Jack, A., \& Young, R.McD. (2010). The Obsessive Compulsive Drinking Scale is a valid Measure of Alcohol Craving in Young Adults. Alcoholism: Clinical and Experimental Research, 34, 2155-2161.

Fortuna, J. L. (2012). The obesity epidemic and food addiction: Clinical similarities to drug dependence. Journal of Psychoactive Drugs, 44, 56-63.

Hackman, A., Bennett-Levy, J., \& Holmes, E. A. (2011). Oxford guide to imagery in cognitive therapy. Oxford: Oxford University Press.

Kavanagh, D. J., Andrade, J., \& May, J. (2005). Imaginary relish and exquisite torture: The Elaborated Intrusion Theory of desire. Psychological Review, 112, 446-467.

Kavanagh, D. J., May, J., \& Andrade, J. (2009). Tests of the Elaborated Intrusion Theory of craving and desire: Features of alcohol craving during treatment for an alcohol disorder. British Journal of Clinical Psychology, 48, 241-254.

Kavanagh, D.J., Statham’ D.J., Feeney, G.F.X, Young, R. McD., May, J. Andrade, J.,\& Connor, J.P. (2013) Measurement of Alcohol Craving. Addictive Behaviors, 38, 15721584. 
Kemps, E., \& Tiggemann, M. (2007). Modality-specific imagery reduces cravings for food: An application of the Elaborated Intrusion Theory of desire to food craving. Journal of Experimental Psychology: Applied, 13, 95-104.

Kemps, E., \& Tiggemann, M. (2009). Competing visual and olfactory imagery tasks suppress craving for coffee. Experimental and Clinical Psychopharmacology, 17, 43-50.

Kemps, E., \& Tiggemann, M. (2013). Olfactory stimulation curbs food cravings. Addictive Behaviors, 38, 1550-1554.

Knäuper, B., McCollam, A., Rosen-Brown, A., Lacaille, J., Kelso, E., \& Roseman, M. (2011). Fruitful plans: Adding targeted mental imagery to implementation intentions increases fruit consumption. Psychology and Health, 26, 601-617.

Leggio, L. (2009). Understanding and treating alcohol craving and dependence: Recent pharmacological and neuroendocrinological findings. Alcohol and Alcoholism, 44, 341352.

Love, A., James, D., \& Willner, P. (1998). A comparison of two alcohol craving questionnaires. Addiction, 93, 1091-1102.

May, J., Andrade, J., Kavanagh, D. J., \& Penfound, L. (2008). Imagery and strength of craving for eating, drinking and playing sport. Cognition and Emotion, 22, 633-650.

May, J., Andrade, J., Panabokke, N., \& Kavanagh, D. J. (2004). Images of desire: Cognitive models of craving. Memory, 12, 447-461.

May, J., Andrade, J., Panabokke, N, Kavanagh, D. J. (2010). Visuospatial tasks suppress craving for cigarettes. Behaviour Research and Therapy, 48, 476-485.

May, J., Andrade, J., Kavanagh, D.J., Feeney, G.F.X., Gullo, M.J., Statham, D., Deas, J., Connolly, J., Cassimatis, M., Young, R.McD., Connor, J.P. (in submission) The Craving Experience Questionnaire: A Brief, Theory-Based Measure of Consummatory Desire and Craving. 
McEvoy, P. M., Stritzke, W. G. K., French, D. J., Lang A. R., \& Ketterman, R. L. (2004). Comparison of three models of alcohol craving in young adults: A cross validation. Addiction, 99, 482-497.

Perugini, M., \& Bagozzi, R. P. (2001). The role of desires and anticipated emotions in goaldirected behaviours: Broadening and deepening the theory of planned behaviour. British Journal of Social Psychology, 40, 79-98.

Saunders, J. B., Aasland, O. G., Babor, T. F., De La Fuente, J. R., \& Grant M. (1993). Development of the Alcohol Use Disorders Identification Test (AUDIT): WHO collaborative project on early detection of persons with harmful alcohol consumption II. Addiction, 88, 791-804.

Statham, D. J., Connor J. P., Kavanagh, D. J., Feeney, G. F., Young, R. M., May, J., \& Andrade, J. (2011). Measuring alcohol craving: Development of the Alcohol Craving Questionnaire. Addiction, 106, 1230-1238.

Tiffany, S. T., \& Wray, J. M. (2012). The clinical significance of drug craving. Annals of the New York Academy of Science, 1248, 1-17.

Versland, A., \& Rosenberg, H. (2007). Effect of brief imagery interventions on craving in college student smokers. Addiction Research and Theory, 15, 177-187. 
Table 1. ACE Imagery by Alcohol Consumption Indices

\begin{tabular}{|c|c|c|c|c|c|c|c|c|c|c|c|}
\hline & \multirow[b]{2}{*}{ Mean } & \multirow[b]{2}{*}{ SD } & \multicolumn{3}{|c|}{ Average Alcohol Per Day } & \multicolumn{3}{|c|}{ 4+ Drinks per Month } & \multicolumn{3}{|c|}{ Max Number of Drinks } \\
\hline & & & $\mathrm{R}^{2}$ & $\beta$ & $r$ & $\mathrm{R}^{2}$ & $\beta$ & $r$ & $\mathrm{R}^{2}$ & $\beta$ & $R$ \\
\hline Predictor (ACE- Imagery) & $\begin{array}{l}\text { Range } \\
\text { (1 to 5) }\end{array}$ & & .143 & & & .160 & & & .120 & & \\
\hline $\begin{array}{l}\text { How often do you picture alcohol or } \\
\text { drinking? }\end{array}$ & 1.71 & 1.00 & & $.156^{* * *}$ & $.34 * * *$ & & $.228 * * *$ & $.38 * * *$ & & $.313^{* * *}$ & $.32 * * *$ \\
\hline $\begin{array}{l}\text { How often do you imagine what it would } \\
\text { taste like? }\end{array}$ & 1.72 & 1.02 & & .086 & $.31 * * *$ & & $.164 * *$ & $.34 * * *$ & & .072 & $.22 * * *$ \\
\hline $\begin{array}{l}\text { How often did you imagine what it would } \\
\text { smell like? }\end{array}$ & 1.61 & 1.00 & & .005 & $.29 * * *$ & & -.024 & $.31 * * *$ & & $-.173^{* *}$ & $.17 * * *$ \\
\hline $\begin{array}{l}\text { How often did you imagine what it would } \\
\text { feel like in your mouth or throat? }\end{array}$ & 1.62 & 1.02 & & -.096 & $.28 * * *$ & & -.092 & $.29 * * *$ & & $-.097^{\mathrm{a}}$ & $.17^{* * *}$ \\
\hline $\begin{array}{l}\text { How often did you imagine how your } \\
\text { body would feel if you had a drink? }\end{array}$ & 1.75 & 1.05 & & $.249 * * *$ & $.35 * * *$ & & $.147^{* * *}$ & $.34 * * *$ & & $.199 * * *$ & $.27 * * *$ \\
\hline
\end{tabular}


Figure 1. Total Imagery Scores by Frequency of Drinking.

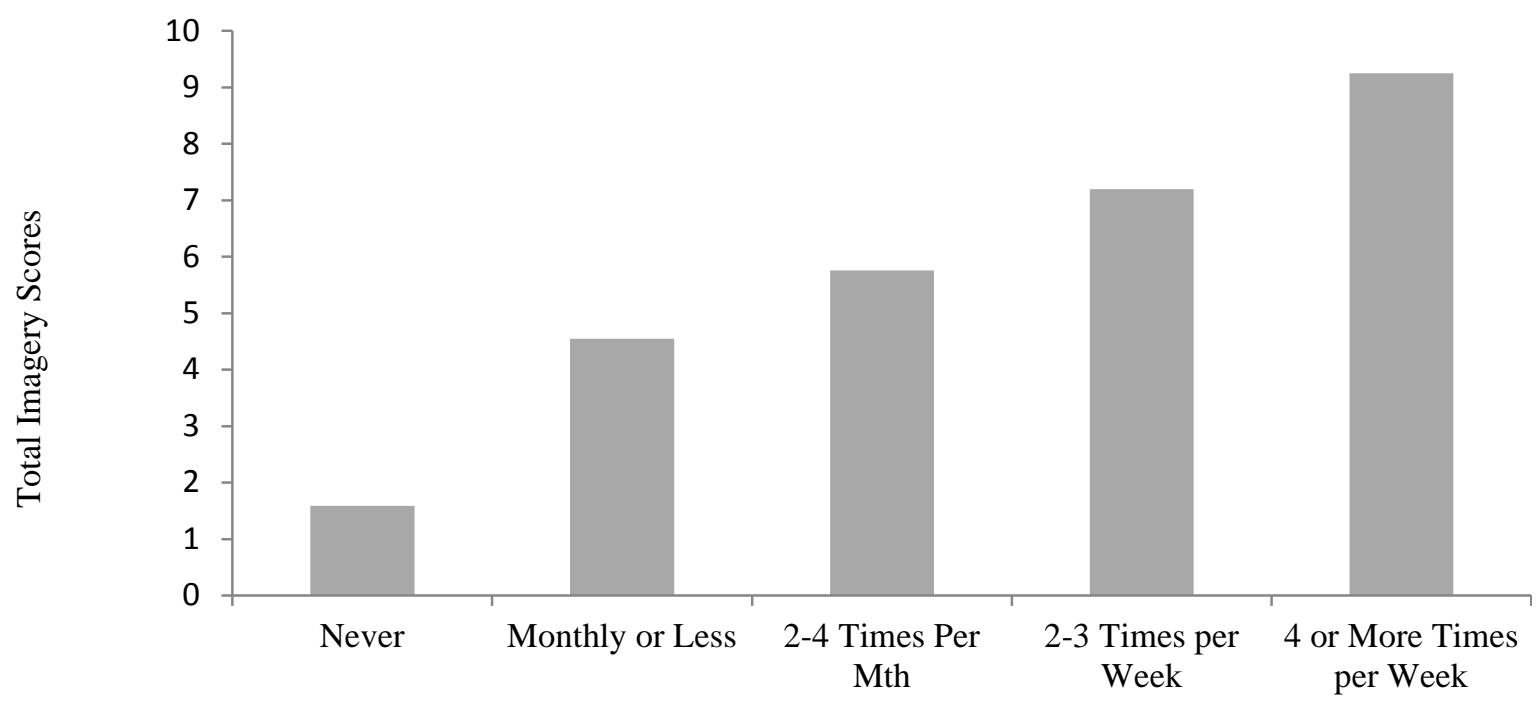

